\title{
Prevalence of the Prescription of Potentially Interacting Drugs
}

\author{
Elena Tragni ${ }^{1 *}$, Manuela Casula ${ }^{1}$, Vasco Pieri' ${ }^{1}$, Giampiero Favato ${ }^{1,2}$, Alberico Marcobelli ${ }^{3}$, Maria Giovanna \\ Trotta $^{4}$, Alberico Luigi Catapano ${ }^{1,5}$
}

1 Epidemiology and Preventive Pharmacology Centre (SEFAP), University of Milan, Italy, 2 Institute of Leadership and Management in Health, Kingston University, Kingston Hill, Kingston upon Thames, Surrey, United Kingdom, 3 Information Flow and Economic Analyses, Regional Health Unit, Marche, Italy, 4 General and Hospital Practice and Drug Policies, Regional Health Unit, Basilicata, Italy, 5 IRCCS Multimedica, Sesto San Giovanni, Milan, Italy

\begin{abstract}
The use of multiple medications is becoming more common, with a correspondingly increased risk of untoward effects and drug-related morbidity and mortality. We aimed at estimating the prevalence of prescription of relevant potentially interacting drugs and at evaluating possible predictors of potentially interacting drug exposure. We retrospectively analyzed data on prescriptions dispensed from January 2004 to August 2005 to individuals of two Italian regions with a population of almost 2.1 million individuals. We identified 27 pairs of potentially interacting drugs by examining clinical relevance, documentation, and volume of use in Italy. Subjects who received at least one prescription of both drugs were selected. Co-prescribing denotes "two prescriptions in the same day", and concomitant medication "the prescription of two drugs with overlapping coverage". A logistic regression analysis was conducted to examine the predictors of potential Drug-Drug Interaction (pDDIs). 957,553 subjects (45.3\% of study population) were exposed to at least one of the drugs/classes of the 27 pairs. Overall, pDDls occurred $2,465,819$ times. The highest rates of concomitant prescription and of co-prescription were for ACE inhibitors $+N S A I D s$ (6,253 and 4,621/100,000 plan participants). Considering concomitance, the male/female ratio was $<1$ in $17 / 27$ pairs (from 0.31 for NSAIDs-ASA+SSRI to 0.74 for omeprazole+clopidogrel). The mean age was lowest for methotrexate pairs (+omeprazole, 59.9 years; +NSAIDs-ASA, 59.1 years) and highest for digoxin+verapamil (75.4 years). In 13/27 pairs, the mean ages were $\geq 70$ years. On average, subjects involved in pDDls received $\geq 10$ drugs. The odds of exposure were more frequently higher for age $\geq 65$ years, males, and those taking a large number of drugs. A substantial number of clinically important pDDls were observed, particularly among warfarin users. Awareness of the most prevalent pDDIs could help practitioners in preventing concomitant use, resulting in a better quality of drug prescription and potentially avoiding unwanted side effects.
\end{abstract}

Citation: Tragni E, Casula M, Pieri V, Favato G, Marcobelli A, et al. (2013) Prevalence of the Prescription of Potentially Interacting Drugs. PLoS ONE 8(10): e78827. doi:10.1371/journal.pone.0078827

Editor: Silvia Alessi-Severini, University of Manitoba, Canada

Received January 14, 2013; Accepted September 16, 2013; Published October 11, 2013

Copyright: (c) 2013 Tragni et al. This is an open-access article distributed under the terms of the Creative Commons Attribution License, which permits unrestricted use, distribution, and reproduction in any medium, provided the original author and source are credited.

Funding: These authors have no support or funding to report.

Competing interests: The authors have declared that no competing interests exist.

*E-mail: elena.tragni@unimi.it

\section{Introduction}

Quality assessment and improvement in health care is a major issue in many countries. Information on healthcare is in demand from policy makers, health-care professionals and the general public. With the majority of doctor-patient encounters in general practice resulting in a prescription for drug treatment, the quality of prescriptions is a critical issue as prescribing drugs has a major influence on patients' well-being, and accounts for a substantial part of health care expenditure.

Drugs are often used in combination to achieve a preferred therapeutic goal or to treat coexisting diseases. Because of the risk related to concomitant use of drugs, co-medication has become a general concern and an important concept in term of prescribing appropriateness. Some combinations may result in undesired pharmacodynamic or pharmacokinetic interactions, resulting in undertreatment or harmful effects [1]. The consequences of drug-drug interactions (DDIs) can range from no untoward effects at all, to drug-related mortality. Although DDIs are considered to be preventable, studies up to $11 \%$ of patients experience symptoms associated with DDIs [2], and DDIs are responsible for up to $2-3 \%$ of hospital admissions $[3,4]$. DDIs are associated with increased health care use $[5,6]$. In the United States, the economic burden of medicationrelated morbidity and mortality is as high as $\$ 177$ billion [7].

Although DDIs are one of the most significant problems with drug prescribing [8], most physicians are not fully aware of all major and clinically important drug interactions $[9,10]$, or 
underestimate the risk of the co-administration of multiple drugs [11]. Furthermore, the pharmacist rarely intervenes when it recognizes the presence of a potentially clinically important DDI [12,13]. Research using prescription databases can contribute to a better understanding of potential DDIs ( $p D D l s$ ); however, only a few studies have examined clinically important DDIs in an outpatient setting, and even fewer have identified patients at risk $[14,15]$.

The aim of this study was to estimate the prevalence of some contraindicated/major/moderate $\mathrm{pDDIs}$ in the population registered under the Regional Health Authority of Marche and Basilicata (central and southern Italy, respectively) during the period 2004-2005, and to evaluate the association of pDDI with available patients' characteristics, as age, gender and number of prescribed drugs.

\section{Methods}

This observational, cross-sectional study was part of the ASSET (Age and Sex Standardised Estimates of Treatment) project [16], a pharmacoeconomic and pharmacoepidemiological study. This analysis focused on data from the Regional Health Departments of Basilicata (a southern Italian region with almost 600,000 inhabitants) and Marche (a central Italian region with almost 1.5 million inhabitants), with a population of slightly more than two million subjects (ASSET population), 1738 general practitioners (GPs) and 244 family paediatricians (FPs).

In Italy, retrospective studies using administrative prescription databases do not require Ethics Committee (EC) protocol approval or notification [17] therefore we did not request approval from the $\mathrm{EC}$, nor consult with the $\mathrm{EC}$ to receive a formal written waiver .

\section{Data sources}

The Basilicata and Marche Regional Health Departments collect prescription data from all Local Health Units of the regions on a monthly basis. These data are grouped in a regional database that can be linked to other administrative databases (e.g. with patients' personal data) using a unique specific identification code. These prescriptions refer only to drugs covered by the Italian National Health Service that are prescribed by GPs and FPs and dispensed by community pharmacies. The regional prescription database includes a full account of product dispensed, dates of prescription and dispensation by community pharmacies, and the personal identification codes for each patient who receives a prescription. All prescriptions were classified according to the Anatomical Therapeutic Chemical (ATC) classification system, as recommended by the WHO [18], and were identified by their AIC (authorisation for marketing) number, which allowed us to determine the specific details and calculate the duration of each prescription (number of units and dosage). The demographic data for patients (sex and date of birth) were available from a regularly updated ad hoc regional database, which could be linked through patient identification keys.

All personal data (name and identification number) were replaced by a univocal numerical code, making both databases anonymous at source in strict compliance with the Italian Privacy Law (Decree 196, 30/06/2003). The study design (observational and retrospective in nature) meant that informed consent was not required from the subjects (Decree 196/03, art. 110).

\section{Choice of drug pairs}

Potential DDIs were identified using the Micromedex $®$ interaction database. In this system, all drug interactions are classified according to two parameters. Clinical relevance is the first, and takes into account potential clinical outcomes, and the type, quality, and relevance of supporting clinical data. The classifications for clinical relevance are: Contraindicated (the drugs are contraindicated for concurrent use), Major (the interaction may be life-threatening and/or require medical intervention to minimise or prevent serious adverse effects), Moderate (the interaction may result in exacerbation of the patient's condition and/or require an alteration in therapy), Minor (the interaction would have limited clinical effects; manifestations may include an increase in the frequency or severity of the side effects but generally would not require a major alteration in therapy), and Unknown. The second parameter is pharmacological documentation: the classifications in this case are Excellent (controlled studies have clearly established the existence of the interaction), Good (documentation strongly suggests the interaction exists, but well-controlled studies are lacking), Fair (available documentation is poor, but pharmacological considerations lead clinicians to suspect the interaction exists, or the documentation is good for a pharmacologically similar drug) and Unknown.

The choice of drug pairs was made according to the following criteria:

- Contraindicated/Major/Moderate for clinical relevance and/or Excellent/Good for documentation;

- High position in the rankings of use in Italy, on the basis of OSMED 2004 (an annual national report on drug utilization and expenditures) [19] for at least one component of the pair.

The components in the pairs could be a drug class or a single molecule.

A total of 27 pairs were identified (Table 1 and Table S1), involving 144 drugs overall (17 single drugs and 8 drug classes).

\section{Potential DDI assessment}

To assess the frequency and distribution of pDDls, all drug prescriptions registered from 1 January 2004 to 31 August 2005 were considered (Figure 1). For each drug pair, people who received at least one prescription were selected to evaluate the presence of pDDls and risk factors. We used defined daily doses (DDDs) from the ATC/DDD system [18] to construct a proxy measure for a day's supply. We assumed a day's supply for a particular prescription to be equal to the total amount of drug in the prescription divided by the DDD.

Several patterns of co-medication can be defined [20]. We investigated two patterns: 
Table 1. List of the 27 pairs.

\begin{tabular}{|c|c|c|}
\hline 1 & Simvastatin-Itraconazole & 15 Simvastatin-Clarithromycin \\
\hline 2 & Metformin-Fluoroquinolones & 16 Betablockers-Verapamil \\
\hline 3 & Omeprazole-Clopidogrel & 17 Simvastatin-Verapamil \\
\hline 4 & Warfarin-Amiodarone & 18 Enalapril-Allopurinol \\
\hline 5 & Warfarin-Moxifloxacin & 19 Warfarin-(nsaids or asa) \\
\hline 6 & Simvastatin-Amiodarone & 20 Methotrexate-(nsaids or asa) \\
\hline 7 & Warfarin-Simvastatin & 21 Enalapril-asa \\
\hline 8 & Digoxin-Verapamil & 22 Enalapril-Metformin \\
\hline 9 & Warfarin-ssris & 23 Warfarin-Itraconazole \\
\hline 10 & Verapamil-Atenolol & 24 Warfarin-Levothyroxine \\
\hline 11 & $\begin{array}{l}\text { Heparines-(Nimesulide, Indomethacin, or } \\
\text { ASA) }\end{array}$ & 25 Simvastatin-Digoxin \\
\hline 12 & Amiodarone-Antiarrythmics la & 26 ace inhibitors-(nsaids or asa) \\
\hline 13 & Methotrexate-Omeprazole & 27 Ssris-(nsaids or asa) \\
\hline 14 & \multicolumn{2}{|l|}{ Simvastatin-Gemfibrozil } \\
\hline \multicolumn{3}{|c|}{$\begin{array}{l}\text { SSRIs: selective serotonin reuptake inhibitors, NSAIDs: nonsteroidal } \\
\text { antiinflammatory drugs, ASA: acetylsalicylic acid, ACE: angiotensin converting } \\
\text { enzyme } \\
\text { doi: } 10.1371 \text { /journal.pone. } 0078827 . t 001\end{array}$} \\
\hline
\end{tabular}

1 Co-prescribing is defined as "the joint prescription of more than one drug by the physician on the same day".

2 Concomitant medication is defined as "the prescription of two drugs with coverage partially overlapping in time, according to information from the pharmaceutical database".

Co-medication may also result from two drugs being available to the patient because they have been dispensed within a certain time period, and some pills are left over. This latter source of co-medication is strictly dependent on the patient's behaviour, while co-prescribing and concomitant medications denote co-medication resulting from the use of drugs as intended by medical doctors.

\section{Statistical analysis}

The unit of analysis was the individual subject. We enumerated individuals exposed to each of the $27 \mathrm{pDDI}$ combinations, counting each individual only once for each combination, irrespective of the number of times he/she was exposed over the 20-month period.

Case-exposure rates to the pDDls were calculated as the number of people exposed to a pDDI divided by the number of individuals receiving one element of the pair. Rates of exposure to the pDDls were calculated for each drug pair, and were expressed as the number of subjects with a pDDI per 100,000 plan participants (PP, i.e., the enrolled population).

A multivariate logistic regression analysis in each drug cohort to determine the factors associated with pDDIs was performed. Exposure to a pDDI (Yes/No) was the dependent variable in the model. Patient characteristics incorporated in the model as independent variables included age (<50 [reference]; 50-64; $65-74 ; \geq 75$ years), gender (male [reference]; female), and the number of medications prescribed ( $<5$ [reference]; $5-9 ; \geq 10$ ). $95 \%$ confidence intervals around each odds estimate were calculated.
All analyses were performed using SPSS ${ }^{\circledR}$ version 16.0.2 (SPSS Inc., IBM Company Headquarters, Chicago, Illinois, USA).

\section{Results}

\section{General prevalence}

The study population included $2,115,326$ participants $(3.6 \%$ of all Italians, population A) (Figure 1).

957,553 subjects (population B) $(45.3 \%$ of the ASSET population) were exposed to at least one of the drugs/classes of the 27 pairs. Of this subpopulation, $18.7 \%$ had at least one overlapping prescription (concomitant patients, population $\mathrm{C}$ ), and $13.2 \%$ received prescriptions of interacting drugs on the same day (patients with co-prescription, population D).

Overall, we counted a mean $\pm S D$ of $13.8 \pm 21.0$ concomitant events per patient, and $5.0 \pm 5.9$ co-prescriptions per patient. In addition, $25 \%$ of patients received at least one concomitant pDDI in more than one pair, up to a maximum of 9 pairs. Considering co-prescriptions, the corresponding percentage decreased to $20 \%$, up to 7 pairs.

\section{Distribution by sex, age and number of prescriptions}

Table 2 (and Table S2) shows the main characteristics of the populations exposed to the 27 pairs of pDDls.

Considering concomitant prescriptions, the male/female ratio was $<1$ in $17 / 27$ pairs of drugs, with the smallest value for the SSRIS + (NSAIDs or ASA) pair (0.45) and the highest value for the omeprazole + clopidogrel pair (2.85). For co-prescription, the male/female ratio was $<1$ in $16 / 27$ pairs of drugs, with the smallest and highest values observed for the same pairs as for concomitant prescriptions ( 0.43 and 3.06 , respectively).

In the cohorts of concomitant prescription-exposed patients, the lowest mean ages $(59.1 \pm 15.7 ; 60.0 \pm 15.4)$ were observed for methotrexate in both of its pairs (+ omeprazole; + [NSAIDs or $A S A]$ ). The mean age of the patients was $\geq 75$ years for only one pair (digoxin + verapamil). In 13/27 cases the mean ages were $\geq 70$ years. The same considerations could be made for patients with co-prescriptions.

In both cohorts (of patients with concomitant or coprescriptions), the mean number of prescribed drugs was $\geq 10$.

\section{Patterns of co-medication}

The rates of concomitant prescription (Table S3) were greatest for persons prescribed with ACE inhibitors + NSAIDs $(6,253.4 / 100,000 \mathrm{PP}), \quad$ SSRIs + (NSAIDs or ASA) $(1,589.7 / 100,000 \mathrm{PP})$, heparines + (nimesulide, indomethacin, or acetylsalicylic acid) (910.0/100,000 PP), enalapril + ASA $(662.0 / 100,000 \mathrm{PP})$ and metformin + fluoroquinolones (428.6/100,000 PP). The same five pairs showed the highest rates of co-prescription events, with the same ranking. The ratio between the subjects with co-prescriptions and the subjects with concomitant prescriptions was 0.81 (the highest) for the digoxin + verapamil pair, and 0.24 (the lowest) for the warfarin + moxifloxacin pair. The most common pDDI was warfarin + NSAIDs (12,492 subjects; 7,581 with concomitant prescription and 2804 with co-prescriptions). 


\section{ASSET POPULATION (A) \\ $\mathbf{N}=\mathbf{2 , 1 1 5 , 3 2 6}$}

POPULATION EXPOSED TO AT LEAST ONE DRUG/CLASS OF THE 27 PAIRS (B)

$N=957,553(45.3 \%$ of $A)$

\section{POPULATION EXPOSED TO AT LEAST ONE CONCOMITANT PRESCRIPTION (C)} $N=178,796(8.5 \%$ of $A ; 18.7 \%$ of $B)$

\section{POPULATION EXPOSED TO AT LEAST ONE COPRESCRIPTION (D)}

$N=126,451(6.0 \%$ of $A ; 13.2 \%$ of $B ; 70.7 \%$ of $C)$

\section{CONCOMITANT EVENTS \\ $\mathrm{N}$ tot $=2,465,819$ \\ $13.8 \pm 21.0$ events/patient}

\section{COPRESCRIPTION EVENTS}

$\mathrm{N}$ tot $=637,244$

$5.0 \pm 5.9$ events/patient

Figure 1. Number and proportion of patients involved in pDDIs.

doi: 10.1371/journal.pone.0078827.g001

\section{Logistic regression analysis}

Table 3 (and Table S4) shows the main results of the logistic regression analysis. With regard to concomitant events, male gender conferred an increased risk of pDDls in 7 pairs for both cohorts of patients, and in 12 pairs for one of the two involved cohorts. The highest adjusted odds ratio (aOR) was present in the omeprazole + clopidogrel pair for patients in the omeprazole cohort (aOR 3.25, 95\% Cl 2.82-3.74). In 4 pairs verapamil + atenolol, betablockers + verapamil, methotrexate + (NSAIDs or ASA), and SSRIs + (NSAIDs or ASA)- male gender decreased the probability of pDDls. The lowest value was observed in the warfarin + levothyroxine pair for the warfarin cohort (aOR $0.41,95 \% \mathrm{Cl} 0.36-0.46)$. In most cases, the aOR values for both males and females were quite close to 1.

Generally, ages $\geq 50$ years were associated with an increased risk; a clear trend was observed in 19 cohorts, with the strongest evidence in the levothyroxine cohort for warfarin concomitance (aORs 2.75 [95\% Cl 2.10-3.61], $6.99[95 \% \mathrm{Cl}$ 5.38-9.07], and 11.26 [95\% $\mathrm{Cl} 8.66-14.63]$ in the three age groups, respectively, vs the $<50$ years class). On the other hand, in one cohort the aOR decreased with increasing age; this was the NSAIDs or ASA cohort for methotrexate concomitance (aORs 0.86 [95\% Cl 0.76-0.98], $0.74[95 \% \mathrm{Cl}$ $0.56-0.73]$, and $0.33[95 \% \mathrm{Cl} 0.28-0.39]$ in the three age groups, respectively).

The number of drugs prescribed to the patient during the study period represented a very strong risk factor for pDDls. Omeprazole + clopidogrel was the pair with most pronounced evidence (omeprazole cohort: aOR 14.12 [95\% Cl 5.21-38.33] for 5-9 drugs; aOR 74.00 [95\% Cl 27.61-198.34] for $\geq 10$ drugs, vs < 5 drugs; clopidogrel cohort: aOR 8.25 [95\% Cl 2.98-22.87]; aOR 21.65 [95\% Cl 7.91-59.28] for 5-9 and $\geq 10$ drugs, respectively). Only in the simvastatin + gemfibrozil pair all aORs were not significant, also if $>1$.

For all analysed risk factors, the aORs for coprescription showed similar patterns, although with milder associations and not always reaching statistical significance (Table $\mathbf{3}$ and Table S4). 
Table 2. Main characteristics of the populations, N (\%).

\begin{tabular}{|c|c|c|c|c|}
\hline & \multirow{3}{*}{$\begin{array}{l}\begin{array}{l}\text { POPULATION A } \\
\text { (ASSET) }\end{array} \\
\mathrm{N}=2,115,326\end{array}$} & \multirow{2}{*}{\multicolumn{3}{|c|}{ POPULATION BPOPULATION CPOPULATION D }} \\
\hline & & & & \\
\hline & & $N=957,553$ & $N=178,796$ & $N=126,451$ \\
\hline \multicolumn{5}{|c|}{ GENDER } \\
\hline \multirow[t]{2}{*}{ Male } & $1,032,357$ & 436,999 & 78,897 & 54,932 \\
\hline & (48.8) & (45.6) & $(43.0)$ & $(43.4)$ \\
\hline \multirow[t]{2}{*}{ Female } & $1,082,969$ & 520,554 & 101,917 & 71,519 \\
\hline & $(51.2)$ & (54.4) & $(57.0)$ & $(56.6)$ \\
\hline$M / F$ & 0.95 & 0.84 & 0.75 & 0.77 \\
\hline \multicolumn{5}{|c|}{ AGE CLASSES, years } \\
\hline \multirow[t]{2}{*}{$<50$} & $1,283,070$ & 406,656 & 16,019 & 9,758 \\
\hline & $(60.7)$ & (42.5) & $(9.0)$ & (7.7) \\
\hline \multirow[t]{2}{*}{$50-64$} & 375,404 & 225,370 & 41,856 & 28,299 \\
\hline & $(17.8)$ & (23.5) & (23.4) & (22.4) \\
\hline \multirow[t]{2}{*}{ 65-74 } & 236,764 & 168,198 & 56,210 & 40,440 \\
\hline & $(11.2)$ & (17.6) & (31.4) & $(32.0)$ \\
\hline \multirow[t]{2}{*}{$>=75$} & 220,088 & 157,329 & 64,711 & 47,954 \\
\hline & (10.4) & (16.4) & (36.2) & (37.9) \\
\hline \multicolumn{5}{|c|}{ PRESCRIBED DRUGS, $n$} \\
\hline \multirow[t]{2}{*}{$<5$} & -- & 406,549 & 13,898 & 9,297 \\
\hline & & (42.5) & (7.8) & (7.4) \\
\hline \multirow[t]{2}{*}{ 5-9 } & -- & 350,488 & 66,723 & 46,210 \\
\hline & & (36.6) & (37.3) & (36.5) \\
\hline \multirow[t]{2}{*}{$>=10$} & -- & 200,516 & 98,175 & 70,944 \\
\hline & & (20.9) & $(54.90)$ & $(56.1)$ \\
\hline
\end{tabular}

\section{Discussion}

Only limited recent data are available on the prevalence of potential DDIs in Italy. The aim of this study was to estimate the prevalence of clinically relevant pDDIs in general practice among the approximately 2 million residents of the Basilicata and Marche regions, and to examine possible predictors of potential DDI exposure.

These analyses suggested that many patients have been exposed to the 27 drug combinations identified as clinically significant, well-documented and widely used in Italy; $8.5 \%$ of the study population received concomitant prescriptions and $6.0 \%$ received co-prescriptions of pDDIs.

Considering persons with at least one potential DDI during the 20-month period, the prevalence estimates applied to the Italian population resulted in 5.02 million people with pDDIs (referred only to the 27 pairs), with females accounting for 2.89 million of these, and persons 65 years of age or older for $67.6 \%$. The occurrence of pDDI events in Italy would be 69,259 million, with a ratio of 1 to 3 of co-prescription vs concomitant events.

Few other studies have evaluated pDDIs in general practice. A retrospective follow-up study of outpatient prescription data in Italy found that among more than 4 million subjects, 8,894 clinically important potential DDIs were identified, representing a 1-year period prevalence of 211 per 100,000 individuals [21]. A register analysis study in general practice carried out in Denmark found that $6 \%$ of the population were exposed to
Table 3. Adjusted odds ratios $(95 \% \mathrm{Cl})$ of concomitant prescription or co-prescription for gender, age, and number of prescribed drugs.

\begin{tabular}{|c|c|c|c|c|}
\hline & \multicolumn{2}{|c|}{ Concomitant prescription } & \multicolumn{2}{|l|}{ Co-prescription } \\
\hline & aOR min & aOR max & aOR min & aOR max \\
\hline & $(95 \% \mathrm{Cl})$ & $(95 \% \mathrm{Cl})$ & $(95 \% \mathrm{Cl})$ & $(95 \% \mathrm{Cl})$ \\
\hline Female & ref & ref & ref & ref \\
\hline \multirow[t]{3}{*}{ Male } & 0.41 & 3.25 & 0.38 & 3.46 \\
\hline & $(0.36-0.46)$ & $(2.82-3.74)$ & $(0.32-0.44)$ & $(2.86-4.17)$ \\
\hline & $\begin{array}{l}\text { for } \\
\text { levothyroxine } \\
\text { concomitance in } \\
\text { warfarin cohort }\end{array}$ & $\begin{array}{l}\text { for clopidogrel } \\
\text { concomitance in } \\
\text { omeprazole } \\
\text { cohort }\end{array}$ & $\begin{array}{l}\text { for } \\
\text { levothyroxine } \\
\text { coprescription } \\
\text { in warfarin } \\
\text { cohort }\end{array}$ & $\begin{array}{l}\text { for clopidogrel } \\
\text { coprescription } \\
\text { in omeprazole } \\
\text { cohort }\end{array}$ \\
\hline $\begin{array}{l}<50 \\
\text { years }\end{array}$ & ref & ref & ref & ref \\
\hline \multirow[t]{3}{*}{$\begin{array}{l}50-64 \\
\text { years }\end{array}$} & 0.86 & 8.44 & 0.86 & 9.76 \\
\hline & $(0.76-0.98)$ & $(7.03-10.12)$ & $(0.75-0.99)$ & $(7.18-13.27)$ \\
\hline & $\begin{array}{l}\text { for metotrexate } \\
\text { concomitance in } \\
\text { NSAIDs-ASA } \\
\text { cohort }\end{array}$ & $\begin{array}{l}\text { for simvastatin } \\
\text { concomitance in } \\
\text { clarithromycin } \\
\text { cohort }\end{array}$ & $\begin{array}{l}\text { for metotrexate } \\
\text { coprescription } \\
\text { in NSAIDs-ASA } \\
\text { cohort }\end{array}$ & $\begin{array}{l}\text { for simvastatin } \\
\text { coprescription } \\
\text { in clarithromycin } \\
\text { cohort }\end{array}$ \\
\hline \multirow[t]{3}{*}{$\begin{array}{l}65-74 \\
\text { years }\end{array}$} & 0.26 & 11.19 & 0.18 & 10.86 \\
\hline & $(0.13-0.49)$ & $(9.31-13.45)$ & $(0.06-0.51)$ & $(7.94-14.87)$ \\
\hline & $\begin{array}{l}\text { for itraconazole } \\
\text { concomitance in } \\
\text { warfarin cohort }\end{array}$ & $\begin{array}{l}\text { for simvastatin } \\
\text { concomitance in } \\
\text { clarithromycin } \\
\text { cohort }\end{array}$ & $\begin{array}{l}\text { for itraconazole } \\
\text { coprescription } \\
\text { in warfarin } \\
\text { cohort }\end{array}$ & $\begin{array}{l}\text { for simvastatin } \\
\text { coprescription } \\
\text { in clarithromycin } \\
\text { cohort }\end{array}$ \\
\hline \multirow[t]{3}{*}{$\begin{array}{l}\geq 75 \\
\text { years }\end{array}$} & 0.20 & 11.26 & 0.15 & 14.89 \\
\hline & $(0.11-0.38)$ & $(8.66-14.63)$ & $(0.05-0.42)$ & $(10.43-21.26)$ \\
\hline & $\begin{array}{l}\text { for itraconazole } \\
\text { concomitance in } \\
\text { warfarin cohort }\end{array}$ & $\begin{array}{l}\text { for simvastatin } \\
\text { concomitance in } \\
\text { levothyroxine } \\
\text { cohort }\end{array}$ & $\begin{array}{l}\text { for itraconazole } \\
\text { coprescription } \\
\text { in warfarin } \\
\text { cohort }\end{array}$ & $\begin{array}{l}\text { for warfarin } \\
\text { coprescription } \\
\text { in levothyroxine } \\
\text { cohort }\end{array}$ \\
\hline $\begin{array}{l}<5 \\
\text { drugs }\end{array}$ & ref & ref & ref & ref \\
\hline \multirow[t]{3}{*}{$\begin{array}{l}5-9 \\
\text { drugs }\end{array}$} & 2.14 & 14.12 & 1.92 & 9.62 \\
\hline & $(1.56-2.95)$ & $(5.21-38.33)$ & $(1.29-2.87)$ & $(3.51-26.37)$ \\
\hline & $\begin{array}{l}\text { for SSRIs } \\
\text { concomitance in } \\
\text { warfarin cohort }\end{array}$ & $\begin{array}{l}\text { for clopidogrel } \\
\text { concomitance in } \\
\text { omeprazole } \\
\text { cohort }\end{array}$ & $\begin{array}{l}\text { for SSRIs } \\
\text { coprescription } \\
\text { in warfarin } \\
\text { cohort }\end{array}$ & $\begin{array}{l}\text { for clopidogrel } \\
\text { coprescription } \\
\text { in omeprazole } \\
\text { cohort }\end{array}$ \\
\hline \multirow[t]{3}{*}{$\begin{array}{l}\geq 10 \\
\text { drugs }\end{array}$} & 3.21 & 74.00 & 3.21 & 47.54 \\
\hline & $(2.97-3.48)$ & $(27.61-198.34)$ & $(2.97-3.48)$ & $(17.67-127.88)$ \\
\hline & $\begin{array}{l}\text { for enalapril } \\
\text { concomitance in } \\
\text { ASA cohort }\end{array}$ & $\begin{array}{l}\text { for clopidogrel } \\
\text { concomitance in } \\
\text { omeprazole } \\
\text { cohort }\end{array}$ & $\begin{array}{l}\text { for ASA } \\
\text { coprescription } \\
\text { in enalapril } \\
\text { cohort }\end{array}$ & $\begin{array}{l}\text { for clopidogrel } \\
\text { coprescription } \\
\text { in omeprazole } \\
\text { cohort }\end{array}$ \\
\hline
\end{tabular}

aOR: adjusted odds ratio

doi: 10.1371/journal.pone.0078827.t003 
potential drug interactions during a 1-year period [22]. In a retrospective analysis of the clinical records from 16 general practitioners in an Italian region, 119 unique severe potential DDIs occurred 1,037 times in 758 patients $(4.7 \%$ of the total number of patients) [23]. Previous studies showed that $0.5-$ $4.0 \%$ of patients are exposed to serious potential drug interactions in primary health care $[1,24,25]$. Differences in the selection of DDIs could explain the differences in the estimated rates. Many lists of potentially interacting drugs are available [26-29], and while there is general agreement on their documentation and clinical relevance, their clinical and economic burden at the population level strongly depends on the drugs in the market at a national level and on prescribing patterns in each local context; this means that comparisons among different settings are most likely irrelevant.

Nevertheless, the evidence from this and other similar studies, as well as those derived from hospitals [30,31] and emergency departments [32,33], show that the pDDIs are a major issue.

In recent years, an enormous quantity of data on drug interactions has been published. Although it is likely that pDDIs are common, only a few of these induce serious adverse events and often only in predisposed patients $[5,33]$. Indeed, in considering the incidence of DDls, we should distinguish between potential interactions and interactions that actually result in clinically adverse effects. In one study [34] of 2,422 patients studied over a period of two months, $113(4.7 \%)$ were taking drugs that could potentially interact, but only seven cases showed any clinical evidence of interaction $(0.3 \%$ of all the patients; $6.2 \%$ of those potentially affected). In a French study [35] overlooking contraindication to the concomitant drug use was the most frequent feature in the cases of non-respect of the Summary of Product Characteristics (38\%), but it was rarely the cause of an adverse drug reaction (6\%). Other studies have also shown that fewer than $11 \%$ of the potential interactions identified for a prescription resulted in an adverse reaction, and these were rarely the reason for hospital admission [36,37]. In a review on hospitalisations and emergency department visits due to drug-drug interactions [38], DDls were responsible for $0.05 \%$ of the Emergency Department visits, $0.57 \%$ of the admissions and $0.12 \%$ of the re-hospitalisations. We should note that these percentages may be an underestimation, because it is possible that medical practitioners and pharmacists did not recognise adverse patient outcomes caused by DDIs [39,40].

Although the percentages are modest, the number of adverse outcomes due to DDls is substantial, because of the large numbers of ED visits and (re-)hospitalisations. Moreover, with certain combinations of drugs, there can be consequences that are very rare but are clinically relevant, or less harmful consequences that arise more frequently. In both cases, the overall burden increases with the number of drug users. For example, in our analysis, NSAIDs-a widely used therapeutic class [41] involved in seven of the selected pairs-showed the highest case-exposure rate in combination with ACE inhibitors $(6,253.4 / 100,000 \mathrm{PP})$. NSAIDs interact with different groups of antihypertensive drugs $[42,43]$, reducing their antihypertensive activity. Although the changes in blood pressure resulting from this interaction are typically small, some patients can experience substantial elevations in both systolic and diastolic blood pressure. A USA study estimated that avoiding minor changes in systolic pressure in patients with osteoarthritis on treatment with NSAIDs would have prevented over 30,000 deaths due to stroke, and over 2000 deaths due to coronary disease [44].

Antibiotics are widely used in Italy, especially those belonging to the class of fluoroquinolones [41]. Blood glucose alterations may occur with fluoroquinolones at a higher incidence than was initially believed [45]. This could be a significant problem for high-risk patients such as diabetics. In our analysis, patients exposed to concomitant prescriptions of metformin and a fluoroquinolone were 428.6/100,000 PP, implying the need for close monitoring of blood glucose in these subjects.

Seven of the selected potential DDI types involved warfarin. Given the narrow International Normalised Ratio (INR) range in which patients should be maintained, even slight increases or decreases in drug concentration in the plasma could have clinically relevant effects. On the other hand, for the same reasons, patients treated with warfarin are strictly monitored, and drug doses are adjusted in accordance with changes in the INR. Since we have no information about the actual administered doses, it is possible that the high prevalence of potential DDIs involving warfarin in our observations has not a high clinical burden.

The only selected pair of drugs with contraindicated concomitant use, simvastatin + itraconazole, showed a very low prevalence in the population (15.8/100,000 PP). The use of itraconazole is not common in primary care, and it is usually administered under specialist care, meaning that few patients are exposed to potentially adverse events resulting from these drug combinations.

Whether two interacting drugs can be used at the same time without serious consequences depends on whether the benefit of both drug therapies outweighs the risk of the DDI, taking into account the availability of alternatives. Our survey assessed separately concomitant prescription and co-prescription. This second case-i.e., the prescription of two potentially interacting drugs on the same day-addresses actual prescriber intention. The intentional act of co-prescribing may reflect a conscious choice, driven by the absence of therapeutic alternatives or accompanied by clear instructions and recommendations to the patient, but it may also indicate a lack of knowledge and preparation on the part of the physician. A survey of prescribers with the Southern California Veterans Affairs Healthcare System found that clinicians correctly identified only $44 \%$ of DDIs [9]. Studies aimed at evaluating pharmacists' knowledge have also found a low recall of DDIs [46,47]. One factor that may complicate health professionals' ability to detect DDls is that the number of possible interactions increases as the number of medications a patient is taking increases [48]; prescribers should recognise that patients often come to them medicated with several drugs, often acquired from multiple sources (e.g., over-the-counter and from other prescribers). Anyhow, physicians cannot be expected to know all of the huge number of pharmaceuticals available and their potential for 
drug interactions. Computerised drug prescribing alerts could help them, but are often overridden because of poor specificity and overload $[49,50]$. If pharmacists are careful to check the dispensed drugs and have a good relationship with the prescriber, they may help to counteract this issue, protecting patient safety and increasing physician's awareness.

In our analyses, the case-exposure rates of co-prescriptions were greatest for ACE inhibitors + NSAIDs or ASA (4,620.6/100,000 PP), SSRIs + NSAIDs or ASA $(884.6 / 100,000$ $\mathrm{PP})$, and enalapril + ASA (517.4/100,000 PP). These data illustrate the extent of the problem of interaction faced by physicians in managing chronic therapies.

We also assessed the extent of the association between some factors and the risk of having a pDDI in the pairs included in the study. In the regression analyses performed for the two cohorts of exposed patients for each drug pairs (overall 54 analyses), the male gender was a risk factor in 25 analyses (with a maximum aOR of 3.25 in the omeprazole cohort for concomitant clopidogrel), an age of $\geq 75$ years was a risk factor in 36 analyses (with a maximum aOR of 11.26 in the levothyroxine cohort for concomitant warfarin), and having 10 or more other prescribed drugs was a risk factor in 50 analyses (with a maximum aOR of 74.00 in the omeprazole cohort for concomitant clopidogrel). Consistent with these results, Cruciol-Souza et al. [51] found that the odds of exposure to potential DDIs were significantly higher in patients aged $\geq 55$ years (OR 1.41) and in those who had been administered more than 7 drugs (OR 9.91). They found, however, that odds of exposure were higher among females (OR 1.23). This difference could depend on list of pDDls choice, or from differences in prescribing habits. In the study by Bjerrum et al., patient-related factors associated with the increased risk of potential drug interactions were a high age and a high number of concurrently used drugs [22]. Gagne et al. found that the odds of exposure were highest among those aged 65 years or older, males, and those with more chronic conditions. The odds of exposure increased by 1.39 times with each addition of a prescription medication [21]. As expected, older age and polytherapy, two conditions that are closely related, greatly increase the risk of interaction; these factors may be used by physicians to identify fragile patients who should receive maximum attention to the potential for DDIs.

The major limitation of our study is that we did not assess the harm associated with potentially hazardous interactions, and therefore the exposure rates may overestimate the real clinical impact of DDIs. It was also not possible to determine whether the choice of drugs was deliberate, and whether it was preceded by a careful evaluation of the risk-benefit ratio (including available treatment options and therapeutic goals) and was accompanied by proper instructions to the patient, to minimise the risk of adverse events. Furthermore, our study was limited by the number and type of interactions evaluated, and by the dataset. First, different results may have been obtained, to the extent that other interactions were selected. Second, similar to many other databases, ASSET depends on the Italian reimbursement system. Consequently, we may not have recognised other potentially serious interactions, and we could have underestimated the actual magnitude of some selected pDDIs (e.g., those involving NSAIDs), since only NHS-covered prescribed medications were included and not OTC non-prescription medications, or herbal and/or home remedies. Drugs dispensed in hospitals and nursing homes were also not included in the study. In addition, the estimated time of prescription coverage based on the DDDs actually provides only a rough evaluation of the timing of use. Finally, we do not know whether the prescribed medicines were taken. This limitation, however, is less relevant if we look at the results from the point of view of the appropriateness of the prescription habits of physicians.

\section{Conclusions}

Limited to the 27 selected drugs pairs, we observed that males, elderly and people taking multiple medications were more frequently exposed to a concomitant or co-prescription of potentially interacting drugs. These results can guide the interventions by health authorities, aimed at containing the epidemiological impact of the pDDIs. On the other hand, the different rates of exposure in the two genders or in the age classes do not involve less attention by the physician in respect of those subjects that showed a lower probability of being exposed to pDDIs. Most importantly, clinicians should recognise that each medication added to a therapeutic regimen significantly increase the risk of patients' exposure to potential DDIs.

The noticeably high number of subjects exposed to pDDls with many of them experiencing multiple episodes during the observation period, and many taking more than one pair of interacting drugs - should encourage health authorities to develop new effective strategies, since the computerised tools available to support the prescription process are not generally used by physicians. We suggest, for example, that an institutional Committee of experts outline a list of DDls based both on the clinical relevance of the interaction and on the prevalence of drug use, thus defining an indicator of appropriate prescribing; this should be evaluated by all regions to have a complete national picture on which educational prescriber-targeted strategies can be drawn.

\section{Supporting Information}

Table S1. Clinical relevance, documentation and level of use of chosen potential Drug-Drug Interactions.

(DOCX)

Table S2. Characteristics of cohorts exposed to potential Drug-Drug Interactions. (DOCX)

Table S3. Event rates in patients with concomitant prescriptions and in patients with co-prescriptions. (DOCX)

Table S4. Logistic regression (panel A: Concomitant prescriptions; panel B: Co-prescriptions). 
$(\mathrm{DOCX})$

\section{Author Contributions}

Conceived and designed the experiments: ET MC GF ALC. Performed the experiments: ET MC. Analyzed the data: ET

\section{References}

1. Astrand B, Astrand E, Antonov K, Petersson G (2006) Detection of potential drug interactions - a model for a national pharmacy register. Eur J Clin Pharmacol 62: 749-756. doi:10.1007/s00228-006-0143-x. PubMed: 16896788.

2. Juurlink DN, Mamdani M, Kopp A, Laupacis A, Redelmeier DA (2003) Drug-drug interactions among elderly patients hospitalized for drug toxicity. JAMA 289: 1652-1658. doi:10.1001/jama.289.13.1652. PubMed: 12672733

3. Grymonpre RE, Mitenko PA, Sitar DS, Aoki FY, Montgomery PR (1988) Drug-associated hospital admissions in older medical patients. J Am Geriatr Soc 36: 1092-1098. PubMed: 3192887.

4. Miranda V, Fede A, Nobuo M, Ayres V, Giglio A et al. (2011) Adverse drug reactions and drug interactions as causes of hospital admission in oncology. J Pain Symptom Manage 42: 342-353. doi:10.1016/ j.jpainsymman.2010.11.014. PubMed: 21454043

5. McDonnell PJ, Jacobs MR (2002) Hospital admissions resulting from preventable adverse drug reactions. Ann Pharmacother 36: 1331-1336. doi:10.1345/aph.1A333. PubMed: 12196047.

6. Shad MU, Marsh C, Preskorn SH (2001) The economic consequences of a drug-drug interaction. J Clin Psychopharmacol 21: 119-120. doi: 10.1097/00004714-200102000-00027. PubMed: 11199940.

7. Ernst FR, Grizzle AJ (2001) Drug-related morbidity and mortality: updating the cost-of-illness model. J Am Pharm Assoc (Wash) 41: 192-199. PubMed: 11297331

8. van Roon EN, Flikweert S, le Comte M, Langendijk PN, KweeZuiderwijk WJ et al. (2005) Clinical relevance of drug-drug interactions : a structured assessment procedure. Drug Saf 28: 1131-1139. doi: 10.2165/00002018-200528120-00007. PubMed: 16329715

9. Glassman PA, Simon B, Belperio P, Lanto A (2002) Improving recognition of drug interactions: benefits and barriers to using automated drug alerts. Med Care 40: 1161-1171. doi: 10.1097/00005650-200212000-00004. PubMed: 12458299.

10. Langdorf MI, Fox JC, Marwah RS, Montague BJ, Hart MM (2000) Physician versus computer knowledge of potential drug interactions in the emergency department. Acad Emerg Med 7: 1321-1329. doi: 10.1111/j.1553-2712.2000.tb00483.x. PubMed: 11073486

11. Ko Y, Malone DC, Skrepnek GH, Armstrong EP, Murphy JE et al. (2008) Prescribers' knowledge of and sources of information for potential drug-drug interactions: a postal survey of US prescribers. Drug Saf 31: 525-536. doi:10.2165/00002018-200831060-00007. PubMed: 18484786.

12. Becker ML, Kallewaard M, Caspers PW, Schalekamp T, Stricker BH (2005) Potential determinants of drug-drug interaction associated dispensing in community pharmacies. Drug Saf 28: 371-378. doi: 10.2165/00002018-200528050-00001. PubMed: 15853439.

13. Malone DC, Abarca J, Skrepnek GH, Murphy JE, Armstrong EP et al. (2007) Pharmacist workload and pharmacy characteristics associated with the dispensing of potentially clinically important drug-drug interactions. Med Care 45: 456-462. doi:10.1097/01.mlr. 0000257839.83765.07. PubMed: 17446832

14. Malone DC, Hutchins DS, Haupert H, Hansten $P$, Duncan B et al. (2005) Assessment of potential drug-drug interactions with a prescription claims database. Am J Health Syst Pharm 62: 1983-1991. doi:10.2146/ajhp040567. PubMed: 16174833.

15. Zhan C, Correa-de-Araujo R, Bierman AS, Sangl J, Miller MR et al. (2005) Suboptimal prescribing in elderly outpatients: potentially harmful drug-drug and drug-disease combinations. J Am Geriatr Soc 53: 262-267. doi:10.1111/j.1532-5415.2005.53112.x. PubMed: 15673350.

16. Favato G, Mariani P, Mills RW, Capone A, Pelagatti M et al. (2007) ASSET (Age/Sex Standardised Estimates of Treatment): a research model to improve the governance of prescribing funds in Italy. PLOS ONE 2: e592. doi:10.1371/journal.pone.0000592. PubMed: 17611624

17. (2008) AIFA. Linee guida per la classificazione e conduzione degli studi osservazionali sui farmaci. GU n. 76. Italy: AIFA

18. World Health Organization W ATC/DDD Index 2009

19. AIFA (2005) Rapporto OSMED 2004. Roma: Ministero della Salute.
MC. Contributed reagents/materials/analysis tools: VP AM MGT. Wrote the manuscript: ET MC GF ALC.

20. Tobi H, Faber A, van den Berg PB, Drane JW, de Jong-van den Berg LT (2007) Studying co-medication patterns: the impact of definitions. Pharmacoepidemiol Drug Saf 16: 405-411. doi:10.1002/pds.1304. PubMed: 16981229.

21. Gagne JJ, Maio V, Rabinowitz C (2008) Prevalence and predictors of potential drug-drug interactions in Regione Emilia-Romagna, Italy. J Clin Pharm Ther 33: 141-151. doi:10.1111/j.1365-2710.2007.00891.x. PubMed: 18315779.

22. Bjerrum L, Lopez-Valcarcel Gonzalez. B, Petersen G (2008) Risk factors for potential drug interactions in general practice. Eur J Gen Pract 14: 23-29.

23. Smith DR, L'Abbate N, Lorusso A (2008) Tobacco smoking among Italian physicians and the role of occupational medicine. Med Lav 99: 3-7. PubMed: 18254534.

24. Bjerrum L, Andersen M, Petersen G, Kragstrup J (2003) Exposure to potential drug interactions in primary health care. Scand J Prim Health Care 21: 153-158. doi:10.1080/02813430310001806. PubMed: 14531506

25. Guédon-Moreau L, Ducrocq D, Duc MF, Quieureux Y, L'Hôte C et al. (2004) Absolute contraindications in relation to potential drug interactions in outpatient prescriptions: analysis of the first five million prescriptions in 1999. Eur J Clin Pharmacol 59: 899-904. doi:10.1007/ s00228-003-0709-9. PubMed: 14685802.

26. Chen YF, Avery AJ, Neil KE, Johnson C, Dewey ME et al. (2005) Incidence and possible causes of prescribing potentially hazardous/ contraindicated drug combinations in general practice. Drug Saf 28: 67-80. doi:10.2165/00002018-200528010-00005. PubMed: 15649106.

27. Magro L, Conforti A, Del Zotti F, Leone R, lorio ML et al. (2008) Identification of severe potential drug-drug interactions using an Italian general-practitioner database. Eur J Clin Pharmacol 64: 303-309. doi: 10.1007/s00228-007-0394-1. PubMed: 17992523.

28. Malone DC, Abarca J, Hansten PD, Grizzle AJ, Armstrong EP et al. (2004) Identification of serious drug-drug interactions: results of the partnership to prevent drug-drug interactions. J Am Pharm Assoc (2003) 44: 142-151

29. Peng CC, Glassman PA, Marks IR, Fowler C, Castiglione B et al. (2003) Retrospective drug utilization review: incidence of clinically relevant potential drug-drug interactions in a large ambulatory population. J Manag Care Pharm 9: 513-522. PubMed: 14664659.

30. Zwart-van Rijkom JE, Uijtendaal EV, ten Berg MJ, van Solinge WW, Egberts AC (2009) Frequency and nature of drug-drug interactions in a Dutch university hospital. $\mathrm{Br} \mathrm{J}$ Clin Pharmacol 68: 187-193. doi: 10.1111/j.1365-2125.2009.03443.x. PubMed: 19694737.

31. Hatton RC, Rosenberg AF, Morris CT, McKelvey RP, Lewis JR. (2011) Evaluation of contraindicated drug-drug interaction alerts in a hospital setting. Ann Pharmacother 45: 297-308. doi:10.1345/aph.1P533. PubMed: 21386026

32. Oertle M. (2012) Frequency and nature of drug-drug interactions in a Swiss primary and secondary acute care hospital. Swiss Med Wkly 142: 0 . PubMed: 23188555

33. Hohl CM, Dankoff J, Colacone A, Afilalo M (2001) Polypharmacy, adverse drug-related events, and potential adverse drug interactions in elderly patients presenting to an emergency department. Ann Emerg Med 38: 666-671. doi:10.1067/mem.2001.119456. PubMed: 11719747.

34. Puckett WH Jr., Visconti JA (1971) An epidemiological study of the clinical significance of drug-drug interactions in a private community hospital. Am J Hosp Pharm 28: 247-253. PubMed: 5094043.

35. Jonville-Béra AP, Béra F, Autret-Leca E (2005) Are incorrectly used drugs more frequently involved in adverse drug reactions? A prospective study. Eur J Clin Pharmacol 61: 231-236. doi:10.1007/ s00228-004-0881-6. PubMed: 15824914.

36. Jankel CA, Fitterman LK (1993) Epidemiology of drug-drug interactions as a cause of hospital admissions. Drug Saf 9: 51-59. doi: 10.2165/00002018-199309010-00005. PubMed: 8347291

37. Jankel CA, Speedie SM (1990) Detecting drug interactions: a review of the literature. DICP 24: 982-989. PubMed: 2244413. 
38. Becker ML, Kallewaard M, Caspers PW, Visser LE, Leufkens HG et al. (2007) Hospitalisations and emergency department visits due to drugdrug interactions: a literature review. Pharmacoepidemiol Drug Saf 16: 641-651. doi:10.1002/pds.1351. PubMed: 17154346.

39. Warholak TL, Hines LE, Song MC, Gessay A, Menke JM et al. (2011) Medical, nursing, and pharmacy students' ability to recognize potential drug-drug interactions: a comparison of healthcare professional students. J Am Acad Nurse Pract 23: 216-221. doi:10.1111/j. 1745-7599.2011.00599.x. PubMed: 21489016.

40. Sorensen TD, Traynor AP, Janke KK (2009) A pharmacy course on leadership and leading change. Am J Pharm Educ 73: 23. doi:10.5688/ aj730223. PubMed: 19513161.

41. AIFA (2006) Rapporto OSMED 2005. Roma: Ministero della Salute.

42. Oates JA (1988) Antagonism of antihypertensive drug therapy by nonsteroidal anti-inflammatory drugs. Hypertension 11: II4-II6. doi: 10.1161/01.HYP.11.3_Pt_2.II4. PubMed: 3280491.

43. Pavlicević I, Kuzmanić M, Rumboldt M, Rumboldt Z (2008) Interaction between antihypertensives and NSAIDs in primary care: a controlled trial. Can J Clin Pharmacol 15: e372-e382. PubMed: 18953082.

44. Hersh EV, Pinto A, Moore PA (2007) Adverse drug interactions involving common prescription and over-the-counter analgesic agents.
Clin Ther 29 Suppl: 2477-2497. doi:10.1016/j.clinthera.2007.12.003. PubMed: 18164916.

45. Mehlhorn AJ, Brown DA (2007) Safety concerns with fluoroquinolones. Ann Pharmacother 41: 1859-1866. doi:10.1345/aph.1K347. PubMed: 17911203.

46. Weideman RA, Bernstein IH, McKinney WP (1999) Pharmacist recognition of potential drug interactions. Am J Health Syst Pharm 56: 1524-1529. PubMed: 10478990

47. Cavuto NJ, Woosley RL, Sale M (1996) Pharmacies and prevention of potentially fatal drug interactions. JAMA 275: 1086-1087. doi:10.1001/ jama.1996.03530380028022. PubMed: 8601923.

48. Karas S Jr. (1981) The potential for drug interactions. Ann Emerg Med 10: 627-630. doi:10.1016/S0196-0644(81)80085-6. PubMed: 7305093.

49. Shah NR, Seger AC, Seger DL, Fiskio JM, Kuperman GJ et al. (2006) Improving acceptance of computerized prescribing alerts in ambulatory care. J Am Med Inform Assoc 13: 5-11. doi:10.1197/jamia.M1868. PubMed: 16221941

50. Weingart SN, Simchowitz B, Shiman L, Brouillard D, Cyrulik A et al. (2009) Clinicians' assessments of electronic medication safety alerts in ambulatory care. Arch Intern Med 169: 1627-1632. doi:10.1001/ archinternmed.2009.300. PubMed: 19786683.

51. Cruciol-Souza JM, Thomson JC (2006) Prevalence of potential drugdrug interactions and its associated factors in a Brazilian teaching hospital. J Pharm Pharm Sci 9: 427-433. PubMed: 17207423. 